\title{
Impressionist Landscape Cartography
}

\author{
Stella W. Todd ${ }^{\mathrm{a}}$ \\ ${ }^{a}$ Metropolitan State University of Denver, Denver, Colorado, USA, toddst@msudenver.edu
}

\begin{abstract}
Cartography helps to show us the world in which we reside by providing us a framework to explore space. We can select myriad themes to represent what is relevant to our lives: physical characteristics, human behaviors, hazards, opportunities. Themes are represented on a continuum between real-world images and pure abstractions. How we define cartography and what we expect from it changes with society and technology. We are now inundated with data but we still struggle with expressing our personal geographic experiences through cartography. In this age of information we have become more cognizant of our individual experience of place and our need to determine our own paths and therefore create our own maps. In order to reflect our journey we can add individual details to cartographic products or generalize information to concentrate on what is meaningful to us. Since time and space are interrelated we experience geography by viewing the landscape as changing scenes over time. This experience is both spatial and temporal since we experience geography by moving through space. Experiencing each scene is a separate event. This paper expands the personalization of maps to include our impressions of the travel experience. Rather than add art to cartography it provides geographic reference to art. It explores the use of a series of quick sketches drawn while traveling along roads using a single drawing pad to produce a time series of interpreted landscapes. With the use of geographic time stamps from global positioning systems these sketches are converted from a drawing to a map documenting the path of movement. Although the map scale varies between sketch entries each scene impression can be linked to one or more maps of consistent scale. The result is an artistic piece that expresses a dynamic geographic experience that can be viewed in conjunction with more traditional maps. Unlike mental maps which are constructed from memory, these maps reflect our direct impressions of the landscape. The use of art can help us convey our experience.
\end{abstract}

Keywords: Impressionist, Landscape, Travel, Geographic, Experience, Map, Cartography

\section{Introduction}

Cartography and art are intertwined. Artists depict geography through landscape and architectural scenes (Cartwright 2009). Both artistic landscapes and maps represent territory (Casti 2015). Maps are graphic artifacts that enhance discourse about territory in relation to the state, the world, the culture, or to propositions for change (Wood 2010). Maps not only represent landscapes but help others navigate them. The path can be scaled relative to one's own experience such as in mental maps or based on a standardized model of space (Gould and White 1986). Art was the early tool of cartographers. The role of art has shifted in relation to science and technology advances.

Since the 4rth century maps became grounded to the Earth's spherical shape and size, and the emphasis on geocentric depictions of spatial relationships continues as the modern cartography paradigm (Slocum 2009). Science and technology transformed cartography into a source of data analysis and location precision. Modern cartography re- placed the documentary aspect of art with a focus on map design and map element perception. Map perception and cognition was achieved through artistic choices of map element colors, placement, and symbolic representation (Slocum 2009).

Geographic perception may be cartographically depicted using a novel techniques such as cartograms, where the size and shape of enumeration units varies with data values of societal perception, or using time-space distortions where time replaces spatial Cartesian coordinates (Dorling 2012; Todd \& Hay 2014). While these techniques help us understand perceptual differences, the data-driven technological depiction of geography fails to provide a realistic viewpoint from the visual and semantic properties of the individual observer, because it is orthographic, and has spatial transformations applied to it (Fairbairn 2009). Mapping the individual experience is further complicated by movement along a path where the observer's geographic perspective changes over time. Here the depth of view varies with the varying distances of objects on the horizon. Therefore mapping a geographic experience requires multiple representations of varying spatial scale that vary relative to position, time, and visual depth.

Dealing with scale variation is an integral part of mapping. Scale is the representative fraction of the product relative to reality. With photographic or digital images scale developed from nadir views varies with terrain relief relative to observation height and sensor properties. When terrain varies so does point scale (Lillesand et. al. 2008). With an orthogonal viewpoint scale refers to the north-south and east-west plane. From the perspective of an observer driving along a road, the scale of viewed objects varies with distance to them. So drawings that realistically depict travel across space will vary in scale. Drawings that depict change of location over time will also vary in scale along the travel 
trajectory unless they occur at regular time intervals from a vehicle travelling at constant velocity. And moving along a windy road presents a longer travel distance than the corresponding map distance between locations. Rather than add art to make a travel map more realistic and personal, spatial reference and context can be added to landscape art in order to enhance the cartographic aspect of the piece. This simply requires an awareness of location, direction of travel as well as information about the environment acquired using traditional mapping methods. Information layers such as topography, vegetation, cultural features, and land use can enhance the artistic impact of a painting or drawing. These parallel views of a geographic space using multiple visual representations tells a more complete story than reliance on any one medium or perspective. Starting with art allows the observer to decide what is important within the landscape by his or her perception of it. The information content then is relevant to the actual experience, in deciding what constitutes the figure or the background (Tufte 1990).

This paper integrates the personal perception of landscapes as expressed in a painting with geographic references. It allows for abstraction of changing landscape elements over time and space as observed from travel via automobile. The purpose is to merge the emotional story of personal geographic experiences with the quantitative and analytical perspectives of modern cartography.

\section{Methods and Results}

The landscape was observed by driving west of Manitou Springs, Colorado in October, 2016, and recording a series of georeferenced photographs and visual observations of landscape elements such as terrain, land use activity, vegetation, historic features, and geology. An artistic impressionist composition of four location observations was com- piled by quickly sketching each location in order to reflect the personal experience of landscape geography as viewed from a moving vehicle. The sketches were then translated to an oil painting composition reflecting the set of experiences along the road. Lastly, map scale was estimated for the painting depicting the travel experience. ESRI Data and Maps was used for roads and cities, a 10m digital elevation model of Manitou Springs was prepared for use by Colorado College was downloaded from ArcGIS online, and EPA data was used for biogeographical regions (Chap- man 2006).

\subsection{Description of Study Area and Geographic References}

The area of interest lies approximately 24-32 kilometers west of the town of Manitou Springs as the crow flies. By road, the area is accessed by driving west on US Highway 24 to the town of Divide and then south on State Highway 67 to Cripple Creek. The study area itself begins at the southern terminus of County Highway 1 in Cripple Creek, Colorado and runs approximately 32 kilometers north-northwest to the highway's northern terminus at US Highway 24 in the town of Florissant, passing through Florissant Fossil Beds National Monument (Figure 1).

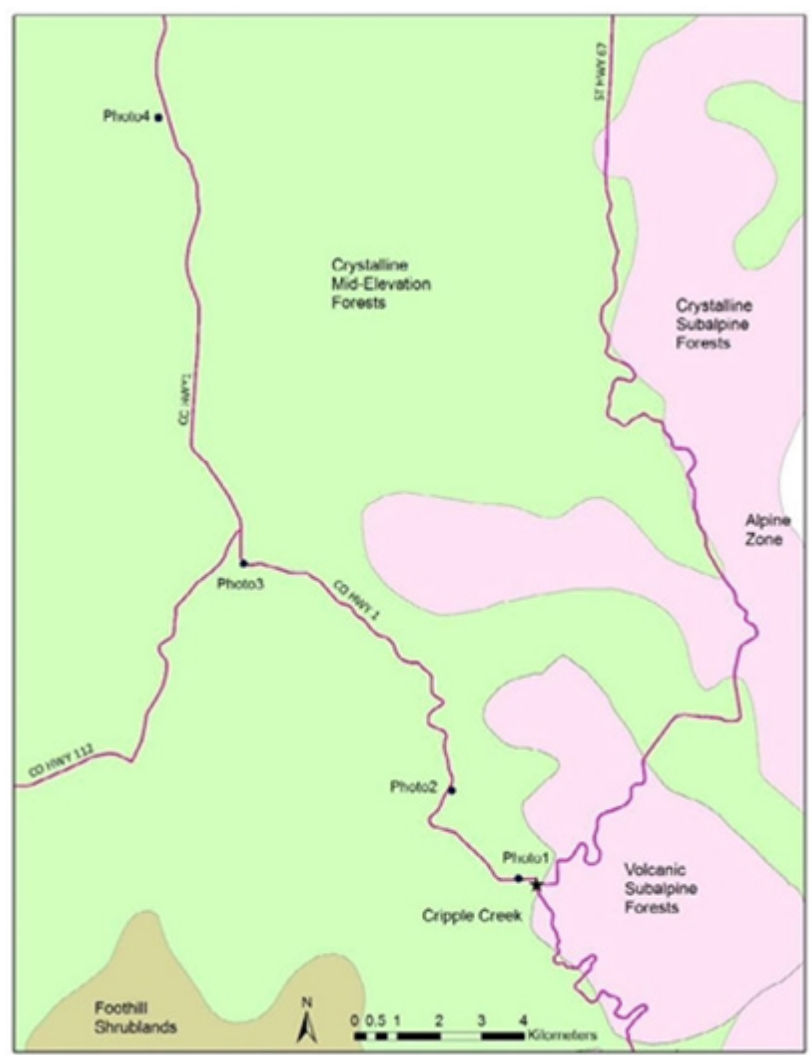

Figure 1: Study Area Showing Locations of Photos and Ecoregions

Manitou Springs is located in the Southern Rockies biogeographical region within Colorado. This area has varied terrain relief associated with Crystalline MidElevation Forests, Crystalline Subalpine Forests, Volcanic Sub- alpine Forests, and Alpine biogeographical regions (Chapman 2006). Low and high mountains characterize the bio- geographical regions (Omernick 1987). Pikes Peak, at $4,301 \mathrm{M}$, is the highest mountain near Cripple Creek and contains the alpine ecoregion visible from the study area, but not observed from the specific landscapes photographed.

The focal points for the four selected landscapes fell within three miles of the Highway 1 transect (Figure 2). Landscape elevations ranged from approximately 3,170 $\mathrm{M}$ in the Gold Hill / Globe Hill mining complex east of Cripple Creek (photo 1) to approximately $2515 \mathrm{M}$ at the Hornbek homestead on Grape Creek in Florissant Fossil Beds National Monument (photo 4). Landscapes were observed primarily within the $2134 \mathrm{M}-2743 \mathrm{M}$ Crystalline Mid-Elevation Forests that contain aspen, ponderosa pine, Douglas fir, and areas of lodgepole pine and limber pine, along with a diverse under- story of shrubs, grasses, and wildflowers. Mule deer and magpies are commonly seen animals in this biogeographical region, and were observed while driving (near photo 3 ). Because of varied elevation it was possible to observe ecoregions other than the one occupied at the photo location. For example the photo 2 landscape is located in 
Crystal- line Mid-Elevation Forests, but the upper portions of the photo shows mountains in the subalpine zone. In the photo 1 landscape, east of Cripple Creek, a small section of Volcanic Subalpine Forests, containing Engelmann spruce, subalpine fir, and aspen forests was observed.

Geology of the area reflects the primarily Crystalline biogeography. The study area sits along the southwest margin of the Pikes Peak Batholith, the dominant geologic feature of the region. This batholith consists mainly of pink to orange Precambrian granitic intrusive material. Pikes Peak granite underlies the entire study area as well as appearing at the surface in forms ranging in size from gravel-like grus to rounded boulders visible at photos 2 through 4 to, and as featured in photo 3, large, rounded spheroidally weathered outcrops (Chronic \& Williams, 2002). Hillslopes and mountainsides near Highway 1 consist mainly of Pikes Peak granite outcrops, while the valley floors consist mainly of Cenozoic volcanics and sediments.

Most of the fossils of Fossil Beds National Monument were laid down in lake shales formed when ash from early Oligocene volcanic activity, around 34 million years ago, primarily from the Thirty Nine Mile Volcanic Field, was deposited within the ancient Lake Florissant outline from Lake George, Colorado through the National Monument lands. Lake Florissant shales contain some of the world's best preserved insect and leaf fossils. Other fossils, such as the giant petrified redwood stumps of Fossil Beds National Monument, were preserved in lahar mudflows through these ash deposits (Taylor, 1999). Overlying these volcanics in the valley floors of photo 2 through photo 4 are more recent loose tertiary and quaternary sediments.

While Cripple Creek gold mining has played a huge role in the economy and development of the study area, the Florissant area is known for its scenic beauty as well as a rich heritage of Paleo-Indians, Utes and Jicarilla Apaches as well as homesteading, mining, and tourism industries (https://www.nps.gov/flfo/index.htm). Similarly, Cripple Creek economies are ranching, tourism, and mining with gold being the most prominent mineral (http://cityof cripplecreek.com). Modern ranching was observed along much of the study area drive, with cattle throughout, and other livestock ranging from Cripple Creek burros and donkeys to horses and llamas / alpacas around Evergreen Station, near photo 2 and the Oligocene mudflow dam which caused ancient Lake Florissant to form.

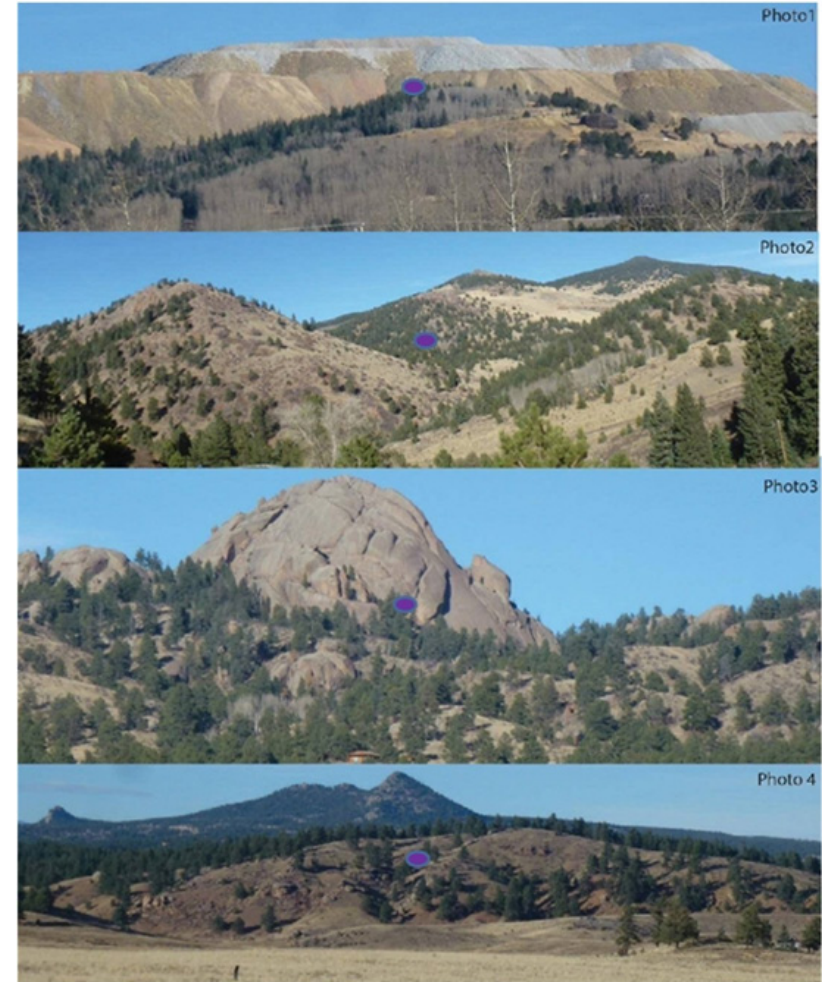

Figure 2: The series of photos taken along the route. GPS longitude and latitude positions were: Photo 1: -105.183 , 38.748, Photo 2: $-105.202,38.767$, Photo 3: $-105.258,38.815$, Photo 4: $-105.283,38.915$. The purple dot indicates the relative center of focus for each photograph.

\subsection{Landscape Art Methods}

Photos were taken along the chosen route driving north from Cripple Creek along County Hwy 1 to Hwy 24. A global positioning system recorded latitude and longitude coordinate positions. Location attributes such as vegetation, wild- life, and historic structures were observed close to the photo locations. Sketches were drawn from the photos using a quick glance approach (Figure 3). 


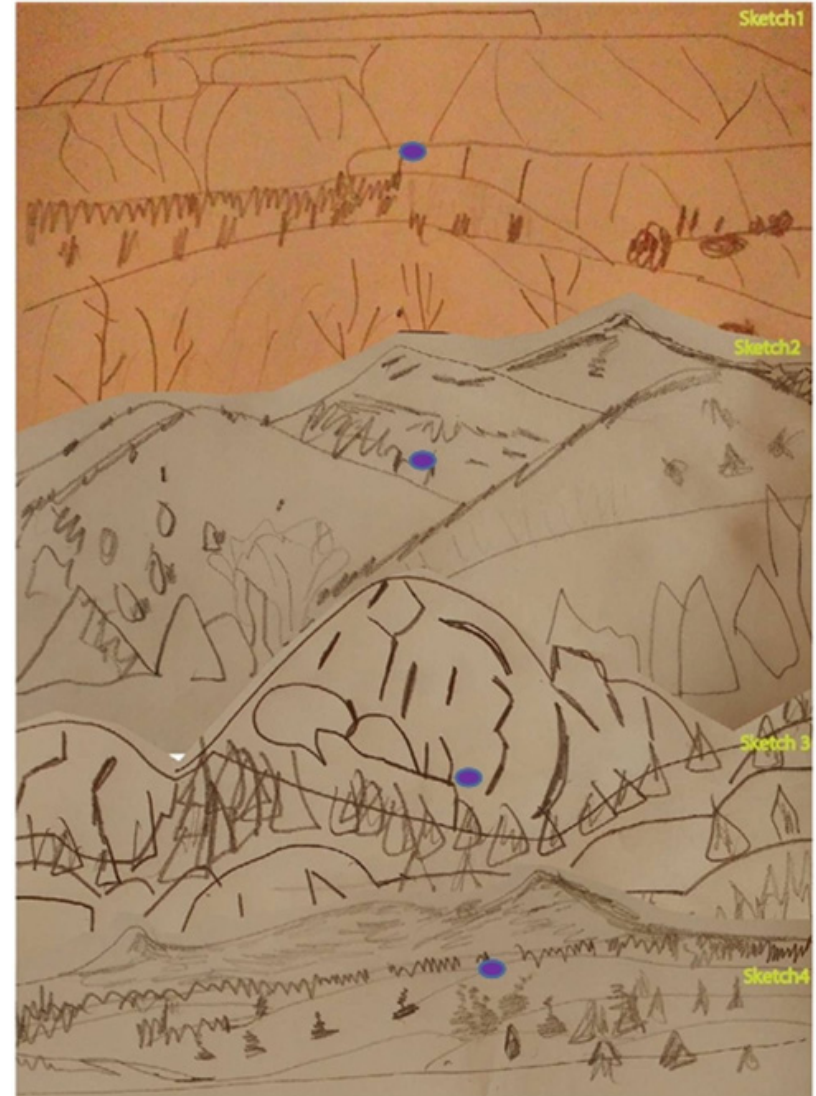

Figure 3: Four sketches corresponding to the four photographs from top to bottom photo1, photo2, photo3, photo4.

Then a painting was created from the series of sketches (Figure 4).

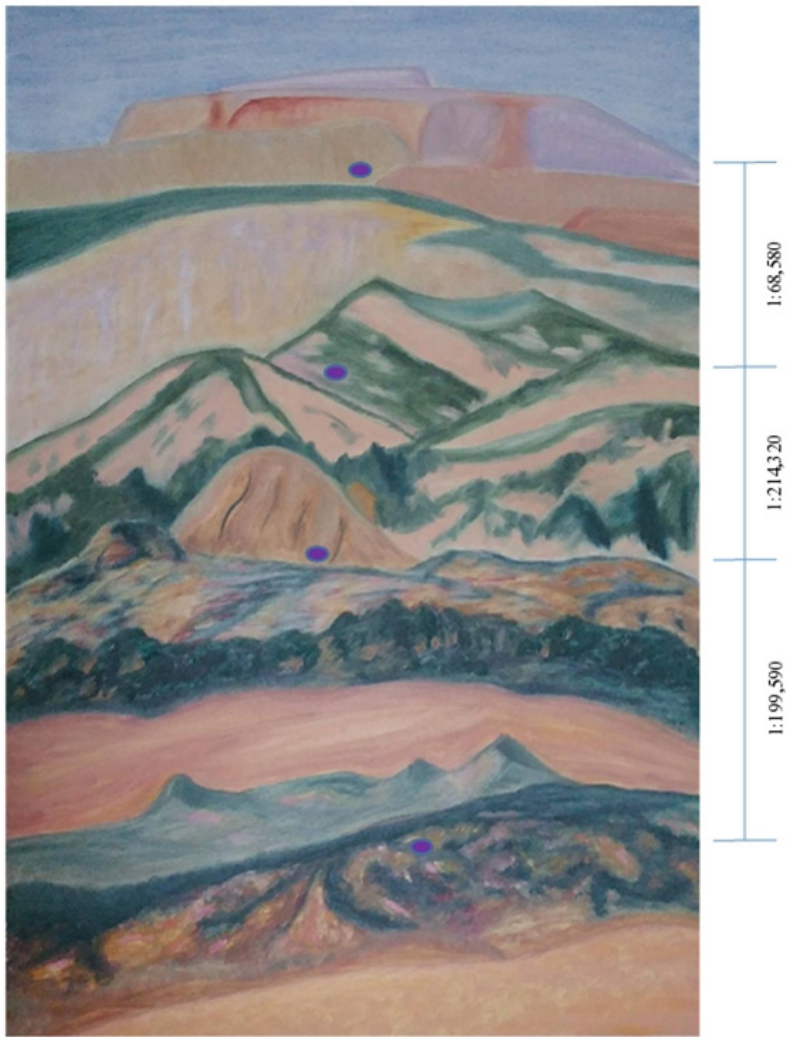

Figure 4: Painting showing changes in landscape along the road from the four sketches. Linear painting scale at publication size determined using distance between photo centers. Photo/sketch locations shown from top to bottom are Photo $1:-105.183$, 38.748, Photo 2: -105.202 , 38.767, Photo 3: -105.258, 38.815, Photo 4: $-105.283,38.915$

\subsection{Map Scale and Viewshed Analysis}

Observations were along or close to roads. Photo 1 was taken outside the car so the viewing direction was different. The depth of observation varied greatly with the possible viewshed that determined the landscape seen from each photo position (Figure 5). Linear map scale was estimated from the relative fraction of the painting dimension in the direction of travel and linear distances between XY coordinates on the road. The map scale across the painting rep- resents a small geographic area and therefore is a relatively large map scale.

Viewshed analysis using elevation data was used to coarsely estimate the visible distances observed within each scene relative to the drawing dimensions. A $10 \mathrm{~m}$ DEM was resampled to $100 \mathrm{~m}$ pixels by averaging elevation values in order to generate a viewshed of terrain visible from the four photo locations. A $100 \mathrm{~m}$ offset was applied to account for a highly variable terrain as well as buildings and other obstructions along the road. The viewshed analysis helps to determine limits to our depth of vision for each location. However no depth or height measurements of visible objects were acquired during this project to verify our actual viewshed dimensions. The azimuth direction of each photograph was estimated using a compass readings.

\subsection{Combining Art and Geographic References}

Results reflect the painting scale of reference as displayed (Table 1). Distance measurements were determined by measuring the ground distance between photos on the 1:100,000 scale map. A straight-line vector was drawn between the photo pairs. Although this produced a zigzag pattern it was treated as a straight road. The painting scale varied between photo locations from less than the 1:100,000 scale map to almost double, using the displayed version. The actual art piece was $60.96 \mathrm{~cm}$ by $91.44 \mathrm{~cm}$

\begin{tabular}{l|l|l|l}
\hline Photos & $\begin{array}{l}\text { Ground } \\
\text { Distance } \\
\text { (M) }\end{array}$ & $\begin{array}{l}\text { Painting } \\
\text { Distance } \\
\text { (M) }\end{array}$ & $\begin{array}{l}\text { Linear } \\
\text { Painting } \\
\text { Scale }\end{array}$ \\
\hline $1-2$ & 2606 & 0.038 & $1: 68,580$ \\
\hline $2-3$ & 7287 & 0.034 & $1: 214,320$ \\
\hline $3-4$ & 10778 & 0.054 & $1: 199,590$ \\
\hline
\end{tabular}

Table 1. Linear painting scale using painting distances relative to ground distance

\section{Conclusions and Discussion}

This study flipped the common assumptions that cartographic products have a consistent spatial scale using a planar view. Here only a linear map scale along the travelled sequence of locations was determined in order to provide geographic context to the interpreted 
experience of the landscape over space and time. The map scale varied between points. The linear scale essentially straightened out the travelled path. Additional measurements of line-of-sight depth measurements to the observed objects and the use of more precise GPS units could help produce a planar scale as well as a more precise linear scale measurement. If a consistent map scale is desired then sketch locations could be determined ahead of travel. Rather than embellish maps with art, geographic reference was added to art. While this type of study views the landscape from the perspective of an individual, and is a type of annotated mental map. More importantly the concept of personal geography includes our experiences from positions along a landscape rather than from a nadir perspective.

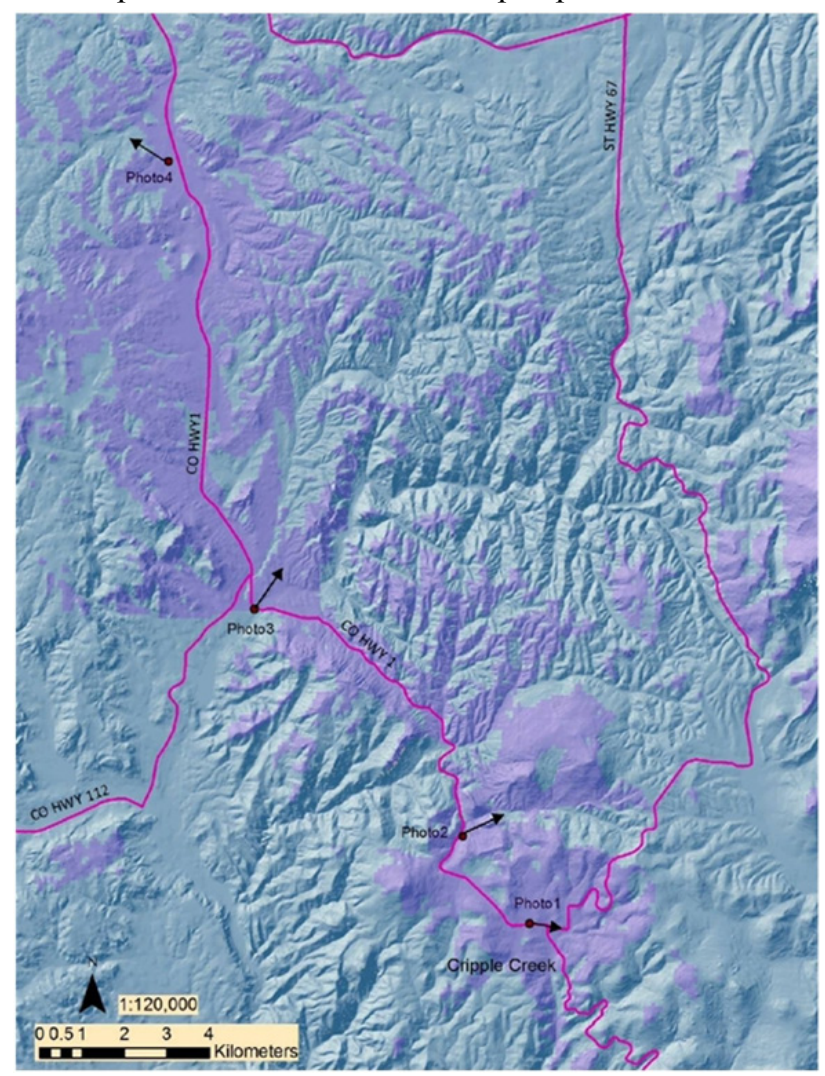

Figure 5: Location of photographs relative to terrain using UTM Zone $13 \mathrm{~N}$ projection. Purple image represents visible and blue non-visible hillshades. Photo true north compass azimuths: photo 1: $105 \mathrm{o}$, photo $2: 58 \mathrm{o}$, photo $3: 35 \mathrm{o}$, photo $4: 320 \mathrm{o}$

Map coordinate positions help future artists, tourists, and cartographers repeat the same path and note their own interpretation of it. In this particular example information was acquired by a two people. Another approach could involve multiple people: a driver, a location recorder, a photographer, a sketch artist. This would allow the artist to focus on sketching his or her perceptions of the changing landscapes along a traveled path rather than on technical details. The result would be similar to that documented here but would yield a direct plein air experience interpreting the landscape. Paintings that give an impression of movement over space and time help connect geography, art, and cartography. Locating subjective experiences of landscape events helps anchor them to geographic cartography.

\section{Acknowledgements}

Support was from grants from MSU Denver school of Letters, Arts, and Sciences, and from the Department of Earth and Atmospheric Sciences. Michael Kiley provided many of the study area descriptions and location verifications.

\section{References}

Cartwright, W. (2009). Art and Cartographic Communication. In Cartwright, W., Gartner, G., Lehn, A., (Eds.), Cartography and Art: Lecture Notes in Geoinformation \& Cartography (pp. 9-21). Berlin: Springer

Casti, E. (2015). Landscape as a Cartographic Icon. In Casti, E (Eds.), Modern Cartography Series, Academic Press (6), 85-115.

Chapman, S.S., Griffith, G.E., Omernik, J.M., Price, A.B., Freeouf, J., and Schrupp, K.L. (2006) Ecoregions of Colorado (color poster with map, descriptive text, summary tables, and photographs): Reston, Virginia, U.S. Geological Survey (map scale 1: 1,200,000).

Chronic, H., \& Williams, F. (2002). Roadside Geology of Colorado. Missoula, MT: Mountain Press Publishing Company Dorling, D. (2012). The Visualization of Spatial Social Structure, Chennai:Wiley.

Fairbairn, D. (2009). Rejecting Illusionism: Transforming Space into Maps and into Art. In Cartwright, W., Gartner, G., Lehn, A., (Eds.),

Cartography and Art: Lecture Notes in Geoinformation \& Cartography (pp. 23-33). Berlin: Springer

Gould, P., \& White, R. (1986). Mental Maps - 2nd Edition. New York: Penguin Books

Lillesand, T.M., Kiefer, R.W., \& Chipman, J.W. (2008). Remote Sensing and Image Interpretation - 6th Edition. John Wiley \& Sons Omernik, J.M. (1987) Ecoregions of the conterminous United States, Annals of the Association of Geographers, 77 (1), 118-125.

Slocum, A.T., McMaster, R.B., Kessler, F.C., \& Howard, H. H. (2009) Thematic Cartography and Geovisualization, Upper Saddle River: Prentice-Hall.

Taylor, A. M. (1999). Guide to the Geology of Colorado. Golden, CO: Cataract Lode Mining Company.

Todd, S.W. \& Hay, C.M. (2014). Time-space Visualization of Automobile Travel Time to Various Destinations from a Starting City. Association of American Geographers Annual Meeting, Tampa.

Tufte, E. (1990). Envisioning Information. Cheshire: Graphics Press

Wood, D. (2010). Rethinking the Power of Maps. New York: Guilford Press 